\title{
Reflexiones sobre la estructura ética del pensamiento de Mary Richmond
}

\author{
Reflections on the ethical structure of Mary Richmond's thought \\ Paz MÉndez-Bonito Zorita \\ College of Public Programs, School of Social Work Arizona State University \\ paz.zorita@asu.edu
}

Recibido: $23 / 05 / 2011$

Revisado: 23/05/2011

Aceptado: 05/06/2011

Disponile on line: $29 / 09 / 2011$

It would ill become us to speak slightingly of the work of those who have handed down to us a precious freight of human sympathy and tenderness. (Mary Richmond, 1899/1969, p. 194)

The radicals think I'm conservative and the conservatives think I'm radical, and they're both surprised that I somehow manage to keep in the procession. (Mary Richmond, 1930, p. 15)

\section{Resumen}

Se examinan las ideas que formaron el pensamiento y la práctica social de Mary Richmond. Se atiende especialmente a dos coordenadas que marcaron su época: el impulso científico, por un lado, y el impulso altruista, por el otro. Nos preguntamos cuáles fueron las respuestas de Mary Richmond a la filosofía pública dominante; de ellas derivamos algunas reflexiones que podrán ser útiles para el presente, especialmente las relativas a una fe en la ciencia como respuesta incontrovertible a los problemas humanos.

Palabras clave: utopía, evangelismo social, cientificismo, caridad científica, personalismo.

\begin{abstract}
The ideas that formed the thought and social practice of Mary Richmond are examined here. Special focus is placed on two markers that defined her times: the scientific impulse on the one hand and the altruistic impulse on the other. We ask ourselves what were Mary Richmond's answers to the dominant public philosophy; from those we derive some reflections that may be useful in the present, especially the ones concerning faith in science as the incontrovertible answer to human problems.
\end{abstract}

Keywords: utopia, social evangelism, scientificism, scientific charity, personalism.

Referencia normalizada: Méndez-Bonito Zorita, P. (2011). «Reflexiones sobre la estructura ética del pensamiento de Mary Richmond». Cuadernos de Trabajo Social, 24: 23-33.

Sumario: Introducción. 1. Años formativos. 2. El momento histórico. 3. Filosofía pública y respuesta de Mary Richmond. 4. ¿Qué fue la Charity Organization Society (COS)? 5. Lecciones y conclusiones. 6. Referencias bibliográficas.

\section{Introducción ${ }^{1}$}

Este año los trabajadores sociales de España celebran con gratitud el ciento cincuenta aniversario del nacimiento de Mary Ellen Richmond, dedicándole este número monográfico. Este artículo intenta ser un acercamiento a la estructura ética de su pensamiento y práctica social. Tres preguntas guían esta exploración: ¿Qué corrientes sociales formaron la ética del pensamiento de Mary Richmond? ¿Cuál fue su respuesta personal al ambiente que nutrió sus ideas? ¿Tiene ella algo que en-

\footnotetext{
1 Todas las citas directas en español son de la autora de este artículo.
} 
señar a quienes ejercen hoy la profesión en el mundo occidental? Un mundo marcado por la abundancia y por el racionalismo técnico aplicado a casi todas las esferas de la actividad humana; pero al mismo tiempo un mundo incapaz de proveer lo más elemental a grandes sectores de la población. Es imposible atender a todos los elementos culturales y fuerzas sociales característicos de la segunda mitad del siglo XIX y primer cuarto del XX que hayan podido influir en Mary Richmond, por tanto me ocuparé principalmente de dos coordenadas: el impulso altruista, por una parte y el impuso científico, por la otra, como ejes claves tanto en la formación de Mary Richmond como en su respuesta a las necesidades sociales de la América con que se encontró.

\section{Años formativos ${ }^{2}$}

Mary Richmond (1861-1928) nació en Belleville en el Estado de Illinois, no muy lejos de donde nació y creció su contemporánea, la otra gran fundadora del Trabajo Social; Jane Addams (1860-1935). Con pocos años fue con su familia a Baltimore, en el Estado de Maryland, de donde procedían sus padres. Quedó huérfana de madre a los tres años y de padre poco después. La tuberculosis reclamó las vidas de ambos, como la de tantos otros en aquella época ${ }^{3}$, la orfandad no era excepcional entonces. Fue criada por su abuela materna y dos tías. Su abuela regía una casa de huéspedes, pero en ese hogar modesto no faltaban ni libros ni tertulias donde se trataban ideas de la época, como el sufragio universal, la vivisección y las cuestiones raciales.

Mary Richmond no fue a la escuela hasta los once años, pues su abuela y sus tías desconfiaban del sistema educativo, pero era una gran lectora y a esa edad ya estaba familiari- zada con autores clásicos de la literatura inglesa. A los 16 años terminó el bachiller (High School) y con él su formación oficial. La falta de mayores credenciales académicas marcó la vida de Mary Richmond porque le impidió una salida profesional como, por ejemplo, la enseñanza. Para mujeres sin dinero y sin conexiones sociales, el Magisterio era una profesión natural para avanzar socialmente y ganar independencia y solvencia económica. Es interesante a este respeto la comparación de Mary Richmond con Jane Addams. Jane Addams tuvo la oportunidad de una escolarización oficial más allá del bachiller, pero también tenía medios económicos y sociales que la liberaban de tener que buscarse la vida ejerciendo una profesión. Curiosamente las dos mujeres, una por falta de oportunidades y la otra por abundancia de ellas, se encontraron en la encrucijada del Trabajo Social pre-profesional. No es de extrañar que la más necesitada de credenciales y capital social, Mary Richmond, fuera la que apostara por la profesionalización de lo que hasta entonces había sido simple trabajo voluntario de «gente bien» o, más humildemente, una ocupación femenina ni bien pagada ni reconocida. Jane Addams, bien sabemos, se resistió a hacer tal apuesta.

En el aspecto religioso no parece que haya tenido una formación sistemática. No hay constancia de que su abuela y sus tías pertenecieran a ninguna iglesia establecida, sino que más bien estaban interesadas en ese vago espiritualismo no infrecuente en aquella época entre la gente culta. Por lo general, estas personas tenían una gran fe en el poder salvífico de la ciencia y eran proclives a las causas progresistas ${ }^{4}$. De todas maneras la estructura social y la sensibilidad cultural de la época eran todavía, con las mati-

2 Mucha de la información biográfica ha sido recogida de fuentes diversas, como: internet, enciclopedias y libros de texto. La información recogida es consistente a través de numerosas fuentes.

3 Durante todo el siglo XIX la tuberculosis fue una gran preocupación en las grandes ciudades de Europa y Estados Unidos. En 1860, en Boston, la mortalidad por tuberculosis ascendía a 400 defunciones por cada 100.000 habitantes. Cifras parecidas se registraban en otras grandes ciudades de la costa oriental del país, como Nueva York y Baltimore (Daniel, Bates y Downes, 1994).

4 El interés en tal espiritualismo procedía, en gran medida, de una actitud cientificista que trataba de hallar las bases naturales y científicas de fenómenos paranormales. Muchos científicos, entre ellos Alfred Russel Wallace (1823-1913), co-descubridor del principio de evolución por selección natural, humanistas como el filósofo Henry Sidgwick (1838-1900) y el psicólogo William James (1942-1910) asumieron el espiritualismo, bien como creencia bien como campo legítimo de estudio. 
zaciones debidas, fuertemente cristianas, específicamente protestantes, y esta sensibilidad influyó decisivamente en Mary Richmond ${ }^{5}$.

Para completar el cuadro anterior y apreciar el contexto en el que Mary Richmond asumió su postura religiosa, es necesario cualificarlo: en las esferas más altas del progresismo, el cristianismo estaba siendo puesto en entredicho. Según esa visión, el cristianismo, y la religión en general, estaban llamados a desaparecer por la pujanza incontestable de la ciencia positiva. John Dewey (1859-1952), buen amigo y colaborador de Jane Addams, y el pedagogo más influyente del país hasta la actualidad, era eficazmente hostil a la religión. El Trabajo Social nació a la sombra, al menos geográfica, de sus dos cátedras: la de la Universidad de Chicago y la de Columbia en Nueva York. Sin embargo, nada en la vida o en los escritos de Mary Richmond indica indiferencia y ni mucho menos hostilidad hacia la religión o el cristianismo. Antes bien, en sus escritos demuestra una y otra vez un aprecio por los beneficios sociales y psicológicos que el pertenecer a una iglesia aportaba a los más necesitados:

[El visitador social] verá la importancia de que [la familia] tenga alguna conexión con la iglesia, e intentará restaurar tal conexión si estuviera rota, urgiendo asistencia a los servicios religiosos y al catecismo de la iglesia a la que la familia de una manera natural pertenezca (1899-1996, p. 177).

Respecto a la eficacia de las iglesias en proporcionar ayuda a los más pobres, dice:

Debemos darnos cuenta que si los pobres van a ser ayudados efectivamente por la caridad, la inspiración debe de venir de la iglesia. La iglesia siempre ha sido y será la fuente principal de energía caritativa (...) En la iglesia y no en ningún otro sitio debemos buscar la devoción organizada que protegerá a los niños de los pobres de la avaricia y el abandono (Richmond, 1889-1969, p. 175).
Capítulo aparte merece su mención al catolicismo. ¿Cuál fue la postura de Mary Richmond al respecto? La pregunta es importante por tres razones. Primero, porque se había criado nada menos que en Baltimore, la archidiócesis madre del catolicismo americano. Su hermosísima catedral, los influyentes concilios de Baltimore, su famoso catecismo, sus numerosas órdenes religiosas (la Ávila de Estados Unidos se denomina), sus instituciones caritativas, educativas y sanitarias constituían una presencia católica, impensable a la vez que amenazante para un país cuyo éxito se predicaba como debido a una cultura protestante (Aranguren, 1952, 1980; Weber, 1904, 1930, 1958). Segundo, dos olas masivas de inmigración -de 1815 a 1860 con 5 millones de inmigrantes y de 1865 a 1914 con 25 millones (Shultz, 1999)trastornaron profundamente la demografía religiosa del país. En la primera ola, un tercio de los inmigrantes eran irlandeses católicos, desplazados de su tierra por la hambruna de la patata ${ }^{6}$. Aún no estaba bien integrada esta empobrecida masa humana cuando aparece en el horizonte la segunda oleada inmigratoria proveniente, en gran medida, de países también católicos como Italia y Polonia. Y la tercera razón para nuestra consideración es que el anti-catolicismo era no sólo grande sino que se producía en todos los estratos sociales: protestantes, creyentes y no creyentes, reaccionarios y progresistas, semialfabetos e intelectuales ${ }^{7}$. Mary Richmond, sorprendentemente, hasta donde he podido averiguar, no manifiesta desconfianza y menos aún oposición al catolicismo. Aunque su sensibilidad religiosa, como veremos, estaba alejada de teologías dogmáticas, su sentido práctico, su contacto con familias desarraigadas y desestructuradas le hacían apreciar la estructura y consistencia que les proporcionaba el catolicismo a sus miembros. Concretamente, Mary Richmond luchó contra el liberalismo matrimonial li-

${ }^{5}$ La iglesia episcopal, aunque minoritaria en número, ejercía una enorme influencia en la cultura del país. Baste considerar que el 32\% de los miembros del Tribunal Supremo han sido seguidores del episcopalismo (concentrados principalmente en el siglo XIX) mientras que como grupo representan menos del $2 \%$ de la población.

${ }^{6} \mathrm{http}$ ://library.thinkquest.org/20619/Irish.html

7 El partido Know-Nothing, atractivo para una masa inculta era cerrilmente anticatólico. 
bertario, tanto civil como religioso, que forzaba a innumerables niñas a uniones abusivas, frecuentemente incestuosas y polígamas (Richmond y Hall, 1925). Es notable la familiaridad de Mary Richmond con la tradición canónica reguladora del matrimonio católico (Richmond y Hall, 1929). Lo contrasta con los sistemas libertarios que condonaban incluso la compraventa de licencias matrimoniales civiles o religiosas. Dice Richmond:

La iglesia católica romana sobresale como el ejemplo más claro de una organización religiosa con reglas definidas, formuladas tempranamente, modificadas de vez en cuando, explicadas y endorsadas ahora a través de todas sus ramas, e interpretadas con mayor detalle por un tribunal eclesiástico» (p. 244).

En otro contexto, hablando de la conexión entre comunidades de fe y sus miembros y la posibilidad de explotación mutua (proselitismo por parte de una fracción y engaño por parte de la otra), compara favorablemente a la iglesia católica con las protestantes:

Los protestantes a menudo critican a la iglesia católica el que espere que los muy pobres contribuyan al mantenimiento de la iglesia. Critican, en su ignorancia, una de las medidas más sabias de la iglesia de Roma en fortalecer su conexión con sus miembros. Los católicos pobres están más inclinados a ver a su iglesia como suya que los protestantes pobres, pues ven que el poder de la iglesia existe para ellos y a través de ellos. Doquiera que la iglesia protestante tiene una fuerte conexión con los pobres, es porque ha esperado de ellos la misma lealtad y abnegación (Richmond, 1899, 1969, p. 174).

Junto con esta actitud pragmática hacia lo religioso, Mary Richmond hizo su elección personal respecto a la religión. A los veinte años, se hizo miembro de la iglesia unitaria, distinguida congregación no cristiana, en cuya escuela dominical -«catecismo» diríamos en español (Sundayschool)- dirigió un grupo de lectura de las obras de Shakespeare. Es un dato importante para entender el punto de vista de Mary Richmond. La iglesia unitaria atraía a las clases más cultas y liberales del país, deseosas de independencia intelectual y llenas de sospechas respecto a las religiones reveladas, con bases dogmáticas y disciplina moral objetiva. Para Mary, esta congregación debió de proporcionarle por una parte, un marco social más definido que el espiritualismo, del que había sido testigo durante su infancia, pero por la otra, también una soltura teológica semejante. Baste como dato que, a falta de un catecismo con contenido al que asentir y que practicar, la iglesia unitaria bien podía ofrecerle las obras de Shakespeare como objeto de estudio en la Sundayschool. Sospecho también, que el realismo que caracterizó a Mary Richmond debió de hacerla algo escéptica de los testimonios de comunicaciones y experiencias del más allá, típicos de las reuniones espiritualistas. En algún escrito, refiriéndose a la experiencia religiosa, comenta sobre la «credulidad» de algunas personas.

Richmond en 1889, a los 27 años, tras una serie de empleos monótonos y mal remunerados, como contable o secretaria o recepcionista, respondió a un anuncio en el que Sociedad para la Organización de Caridad, la Charity Organization Society (COS), buscaba un asistente de tesorero para su sucursal en Baltimore. Consiguió el trabajo y sólo dos años más tarde ya era la directora de la organización en Baltimore. Dice Max Siporin (1968) acerca de Mary Richmond en su nuevo empleo: «Pareció revivir en este papel (...) identificándose completamente con su trabajo prestando asistencia a los pobres de Baltimore» (Siporin, 1968, p. vii). En la COS, inesperadamente, encontró Mary Richmond la vocación de su vida, el eje de su autoformación y de su capacidad creadora, así como la fuente de conexiones sociales que facilitarían su labor de reforma social. En este momento Richmond se transforma en persona pública. Todas las notas biográficas apuntan hacia esta dimensión de su vida. No se casó, se dedicó totalmente a la profesión, escribió varios libros, casi todos referidos en la lista bibliográfica de este trabajo, y numerosos artículos.

\section{El momento histórico}

Mary Richmond nace el mismo año en que empieza la guerra civil americana (1861- 
1865), un conflicto que enfrentó a los estados del norte, liderados por el Presidente Abraham Lincoln, contra estados del Sur que querían separarse de la Unión Federal para defender, entre otras cosas, la institución de la esclavitud. La contienda causó la enormidad de 617.000 muertos (un dos por ciento de la población) y 375.000 heridos (Encyclopaedia Britannica, p. 730) ${ }^{8}$. Las consecuencias sociales en términos de viudedad, orfandad e invalidez física fueron incalculables: aumentó el número de familias desmembradas por enfermedades como la tuberculosis y contribuyó al número de invalideces físicas que crecerían pocos años después todavía más, como consecuencia del furioso desarrollo industrial. Al mismo tiempo la guerra estimuló el desarro1lo industrial de los estados vencedores, la expansión de la frontera Oeste (en parte para financiar la guerra del lado federal), y en lo político dio lugar, por fin, a la emancipación de 200.000 personas que habían estado sometidas hasta entonces a esclavitud ${ }^{9}$. La guerra civil sorprendió a la familia Richmond en Illinois, Estado afiliado a la causa federal. Con tres años, Mary Richmond regresó, como dije, a Maryland, Estado fronterizo durante la contienda, donde sin duda fue expuesta a los resentimientos posteriores entre vencedores y vencidos, y donde tuvo que ver con sus propios ojos el fenómeno de cientos de ciudadanos de origen africano libres, por fin, pero no necesariamente dueños aún de su destino económico, político y social ${ }^{10}$. En ese contexto de cambio y dislocación social, el hogar de Mary le ofrecía un ambiente liberal desde el que entender y juzgar las cuestiones raciales.

Otro fenómeno demográfico que marca el tiempo histórico de Mary Richmond es la ya mencionada masiva inmigración de Europa. A la masa de inmigrantes procedentes de una Irlanda pauperizada, hambrienta y católica, le sigue la segunda gran inmigración de países de fuera de la influencia británica (Italia, Polonia, Alemania y Rusia) y fuera de la esfera protestante (católicos, judíos y ortodoxos). La necesidad de americanizar a los 25 millones de la mayoría de los recién llegados se hace patente. Las discontinuidades lingüísticas, religiosas, culturales y económicas eran grandes y hacían la labor de integración social tan urgente como difícil. Jane Addams y su equipo de Chicago respondieron a este reto con la creación de la casa de asentamiento, Hull House. Mary Richmond respondió con lo que ella llamaba retail (al por menor) o trabajo individualizado, como complemento de lo que llamaba wholesale (al por mayor): el trabajo comunitario típico de las casas de asentamiento (Siporin, 1968). Frente a la estimación de Siporin, que critica a Mary Richmond por su falta de conciencia respecto a las diferencias étnicas y raciales, esta autora usa una lengua digna de los más delicados requisitos de sensibilidad cultural. Distingue entre uniformidad e igualdad. Comenta, por ejemplo, que «algunas de las tonterías que se hacen hoy en nombre de la americanización derivan directamente de creer que todos los inmigrantes son esencialmente lo mismo y deben ser tratados como tales»» (Richmond, 1922, p. 154). Señala lo antidemocrático de las políticas sociales que tratan de imponer un tratamiento homogéneo para todos, al mismo tiempo que subraya la humanidad común de los seres humanos: «en sus relaciones primarias, sus luchas, sus errores, su necesidad de orientación, su derecho a oportunidades, a su desarrollo, y a la diversidad» (p. 152).

\section{Filosofía pública y respuesta de Mary Richmond}

Ideológicamente en la época de Mary Richmond son de destacar: por una parte, el gran

${ }^{8}$ En 1860 había 31.183.582 personas censadas en Estados Unidos (http://www.civil-war.net/pages/1860_census.html).

${ }^{9}$ La esclavitud se abolió legalmente en Estados Unidos en diciembre de 1865 con la ratificación del Thirteenth Amendment, que declaraba: «Ni esclavitud ni servidumbre involuntaria, excepto como castigo por un crimen castigable del que el interesado haya sido convicto, existirá en los Estados Unidos u otro lugar sujeto a su jurisdicción» (Constitución de los Estados Unidos).

${ }^{10}$ Los ciudadanos de origen africano adquirieron el voto en 1870 con la aprobación del XV Amendment de la Constitución, pero no obtuvieron todos los derechos civiles hasta 1968 con el Civil Rights Act. 
movimiento religioso, llamado The Social Gospel (el evangelio social), y por la otra, el cientificismo o positivismo científico a ultranza. El evangelismo social fue un impulso del liberalismo protestante y es característico de Estados Unidos. Se desarrolló entre 1870 y 1930 como respuesta a las consecuencias sociales brutales de una industrialización masiva y rápida. El evangelismo social proponía aplicar principios de justicia derivados de la tradición bíblica, alejándose de una religiosidad individualista y privada, e instaba a los creyentes al activismo social. El movimiento partía de concebir al ser humano como fundamentalmente bueno, interdependiente y muy maleable a la persuasión hacia el bien. Fue un movimiento más optimista que realista y hasta cierto punto simplista. Decayó en los años 1930, bajo el peso por una parte, de expectativas frustradas y, por la otra, de perspectivas teológicas más complejas -la propuesta por Reinhold Niebuhr, por ejemplo- pero no se puede comprender el activismo social de los líderes de la COS o de los líderes de las casas de asentamiento sin contar con el ardor religioso del evangelismo social (Duff, 1967). La actividad reformadora de Mary Richmond es un producto de este ambiente.

El mismo optimismo y la simplicidad filosófica que se contemplan en el evangelismo social teñían el cientificismo, la otra gran coordenada ideológica de la época. Básicamente consiste en creer que sólo la ciencia y sus métodos tienen acceso a la verdad. Otros campos de estudio, como la filosofía, la ética, la teología o la estética se consideran saberes espurios, pues la única realidad es la que puede conocerse a través del método científico. Era inevitable que los espectaculares avances de la ciencia en las últimas décadas del siglo XIX dieran lugar también a una fe desmedida en el progreso. La ciencia, se creía, daría respuesta satisfactoria a todos los problemas humanos y haría progresivamente innecesaria la religión. La religión era vista por estos ideólogos como una cortapisa al avance humano o, más benignamente, como un estadio intermedio, estadio que había que tolerar hasta que la ciencia diera, por fin, la solución definitiva a la sucesión del problema de la condición humana. El cientificismo impregnó lo que hasta entonces se habían llamado "ciencias morales.» Las nuevas ciencias sociales y las tecnologías acompañantes, desprovistas ya de todo aparato metafísico y de toda cuestión relativa al origen y fin del ser humano, desnudas de toda amarra a realidades intangibles, «desencantaron» la vida, según la acertada frase de Max Weber (1919, p. 204). Estas ciencias vinieron a dominar todos los campos del saber sobre el ser humano. La racionalidad técnica hizo el resto, llevando a todo el tejido social la aplicación práctica del nuevo quehacer científico.

El envite del positivismo dio como resultado la descalificación de todo fundamento objetivo del juicio moral y, en su lugar, el emotivismo moral tomó carta de residencia en la universidad y en las esferas más influyentes de la opinión pública. Las bases objetivas de la moralidad se vieron relegadas cada vez más a los guetos religiosos ${ }^{11}$. Esta situación, arguye MacIntyre (1984), derivó inevitablemente hacia una moral puramente utilitaria basada, al fin y al cabo, en la ley del más fuerte; en otras palabras: en las emociones y preferencias del que más puede. Tristemente el evangelismo social, enamorado también del progreso y con firme creencia en la ciencia, no fue capaz de atemperar la crudeza de las demandas del positivismo y de la racionalidad técnica.

Uno de los descubrimientos científicos que más influyeron en la filosofía pública del país fue el principio de selección natural (Darwin, 1809-1882). La teoría de Darwin (1959) fue pronto usada como punto de apoyo para afirmar la superioridad de la raza blanca, más concretamente la de los pueblos anglosajones. No siendo bastante, el racionalismo técnico requería que el nuevo «descubrimiento» informara la política social del país. El darwinismo social de Herbert Spencer (1820-1903) tuvo una aceptación prácticamente incontestada entre la clase dirigente de Estados Unidos. Encontró un campo especialmente fértil entre los

11 Las raíces filosóficas del subjetivismo moral se encuentran en Kant. Para una exploración profunda de los orígenes del subjetivismo moral, véase Alasdair MacIntyre (1984, 1988, 1990). 
progresistas sociales, incluso entre líderes del evangelismo social. Uno de los capítulos más tristes de la historia de la lucha por la justicia social fue la corrupción de activistas de buena voluntad por la cultura eugenésica del país. Para calcular el poder de la cultura eugenésica en la época de Mary Richmond es necesario recordar algunos nombres asociados a las leyes eugenésicas o a su promoción cultural: Oliver Wendell Holmes (1841-1935), miembro del Tribunal Supremo de 1902 a 1932; Andrew Carnegie (1835-1919), fundador de cientos de bibliotecas públicas; la familia Rockefeller, cuyas fundaciones filantrópicas abarcan desde la segunda mitad del siglo XIX hasta hoy; Andrew William Mellon (1855-1937); Margaret Sanger (1883-1966), fundadora de la mayor organización nacional e internacional proveedora de servicios de aborto y planificación familiar en nuestros días, la Planned Parenthood ${ }^{12}$.

El triunfo de la eugenesia y la falta de oposición de las iglesias cristianas en general $^{13}$ y de los evangelistas sociales en particular se refleja y resume en la importante opinión del Tribunal Supremo sobre Buckv. Bell (1927), escrita por Oliver Wendell Holmes. Merece la pena explicarla y citarla, pues su lengua penetró en el léxico popular y perdura hasta nuestros días. El caso se refiere a una mujer, Carrie Buck, de la que se decía que poseía una inteligencia inferior a lo normal. La opinión judicial determinó que podía ser esterilizada a la fuerza, pues el interés del Estado en la «pureza» o salud genética de la población sobrepasaba el derecho individual a la integridad física. Traduzco a Holmes cuando dice:

Hemos visto más de una vez que el bienestar público puede pedir la vida de los mejores ciudadanos. Sería extraño que no pudiera pe- dir sacrificios de menos calibre a aquellos que ya chupan la savia del Estado -sacrificios que muchas veces ni siquiera les importan muchopara prevenir que seamos aplastados por incompetentes. Es mejor para el mundo, que en vez de esperar a ejecutar por su crimen a hijos degenerados o dejarlos morirse de hambre por su imbecilidad, que la sociedad pueda prevenir que aquellos que son manifiestamente inútiles continúen reproduciéndose. El principio que sostiene la vacunación obligatoria es bastante amplio para cubrir también el corte de las trompas de Falopio (...) Tres generaciones de imbéciles es bastante.

Después de esta decisión judicial, un Estado tras otro de la Unión aprobaron las leyes de esterilización forzosa. La única institución del país que levantó la voz consistente y fuertemente fue la iglesia católica ${ }^{14} \mathrm{y}$, por lo que parece, no hubo disensión al respecto por parte de la generalidad de sus miembros ${ }^{15}$ (Rosen, 2004; Leon, 2005).

Mary Richmond desarrolló, pues, su trabajo no sólo dentro de una cultura eugenésica, sino que muchos de sus asociados, aquellos de los que ella esperaba liderazgo intelectual y moral, fueron presa de esa filosofía pública. ¿Cuál fue la respuesta de Mary Richmond a la oferta eugenésica, una oferta progresista y popular que prometía resolver el problema de la pobreza de una manera científica, racional y aparentemente compasiva? Sabemos que utilizaba el Eugenics Record Office, fundado en 1919, como fuente de información para sus investigaciones sociales y lo recomendaba como recurso a los trabajadores sociales. Sin embargo, hasta donde he podido averiguar, Richmond mantuvo una actitud, si no incisivamente crítica, al menos no activista en el movimiento. Podemos incluso discernir en sus escritos una posición en gran parte defendible por derecho natural respec-

12 Pocos conocen hoy la filosofía racista en el origen de Planned Parenthood, su conexión con el Negro Project y la simpatía de Margaret Sanger por la política eugenésica de la Alemania hitleriana.

13 El Comité on Cooperation with Clergymen of the American Eugenics Society promovía concursos de sermones a favor de la eugenesia. Los mejores sermones se publicaban e iban acompañados de premios monetarios.

14 El único voto en contra de la decisión Buck v. Bell fue el del juez católico, Pierce Butler.

15 Dos sacerdotes católicos, John A. Ryan y Montgomery Cooper, participaron en la American Eugenics Society, pero mantuvieron una posición crítica de los fundamentos científicos de la eugenesia y lucharon contra los prejuicios raciales y de clase que cundían en la organización. Abandonaron la Society tan pronto como la eugenesia fue condenada por Pío XI, en 1930, en la Encíclica Casti Connubii. 
to a los derechos y límites del Estado en relación a la familia:

El matrimonio, por tanto, no es un contrato «como cualquier otro», tampoco es un derecho natural incuestionable e indiscutible. Es un derecho ligado por todos los lados a deberes. Es un contrato diferente de todos los demás en el sentido de que, para el bien del individuo y el bienestar público, debe estar limitado por el Estado con condiciones no requeridas para otros contratos (Richmond y Hall, 1929, p. 335).

Enumera qué condiciones deben ser reguladas por el Estado: grado de consanguinidad, afinidad, edad mínima, prevención de fraude y coerción. Hasta aquí no hay nada objetable a la posición de Mary Richmond desde el punto de vista del derecho natural, pero añade a continuación que el Estado puede impedir uniones que «transmitan defectos o enfermedades comunicables.» En este punto particular es hija de su época. Pero aún así manifiesta una gran cautela respecto hasta dónde puede intervenir el Estado sin infringir daños:

Y sin embargo, hay límites más allá de los cuales el Estado no procede sin arriesgarse. Su parte en el contrato matrimonial, aunque importante, es restringida (...) hay poca justificación (...) para una regulación por parte del Estado de cada detalle. Muchos aspectos del matrimonio (...) no pueden mejorarse con legislación o administración pública (p. 335).

Más allá de este principio, su posición práctica respecto a la eugenesia se resume cuando afirma que es muy difícil usar las leyes matrimoniales para controlar la transmisión de enfermedades contagiosas y mucho más difícil aún respecto a enfermedades mentales y retraso mental (op. cit.). En cuanto al papel de los trabajadores sociales en el proyecto eugenésico, Richmond es contundente. En la obra Social Diagnosis (1917), el libro por el que es más conocida y en el que se detallan con gran precisión los múltiples componentes para investigar sobre la historia social de una familia, dice: «Ir tan lejos como lo que requiere la investigación eugenésica, está naturalmente fuera de lugar» (1917, 1965, pp. 186-187). Aquí, a mi juicio, de- muestra una actitud contracultural no despreciable hacia una injusticia aceptada y muchas veces promovida por «los mejores.»

Le importaba a Mary Richmond promover familias sanas, fundadas con libertad por parejas estables, comprometidas con el bienestar de los hijos y, por tanto, comprometidas para siempre a una vida en común. Le preocupaban muchísimo los matrimonios forzados y de menores y a este tema dedicó un libro entero (Richmond, 1925). Veía que el Estado y las comunidades religiosas debían intervenir incrementalmente en los cambios necesarios para proteger a los más débiles. Por esta razón desaprueba los matrimonios basados en $\mathrm{co}$ monlaw: «El estado que aún reconoce los matrimonios de commonlaw rebaja los estándares de todos los matrimonios.» (Richmond y Hall, 1929, p. 339). Y en alguna página anterior: «la responsabilidad del estado es no sólo ver que el contrato se mantiene para los dos que lo hacen, sino para todos aquellos a quienes concierne vitalmente» (p. 332).

No ignora fuerzas sociales que, por lo menos a corto plazo, pueden militar contra el bienestar de la familia. Por ejemplo reconoce que el derecho al voto, conquistado por las mujeres en 1918, abriría paso a una mayor justicia en relación a las leyes del matrimonio (Richmond y Hall, 1929). Pero también ve en el movimiento feminista una amenaza para las mismas mujeres y para la familia:

Durante el primer año del sufragio federal de las mujeres se hizo un decidido esfuerzo para deshacer las protecciones legales que el trabajo social había creado poco a poco respecto (...) al empleo industrial. En nombre de una igualdad que no significaba más que uniformidad, algunas mujeres (...) buscaron la abolición de toda esta legislación protectora (Richmond, 1922, pp. 152-153).

Igual que ocurre hoy, también en el tiempo de Mary Richmond la familia como institución era atacada en ciertos círculos intelectuales Sin embargo, no se deja seducir por argumentos que más bien parecen un juego intelectual de la gente acomodada. Pone como ejemplo el testimonio de una trabajadora social que dice:

Cuando estaba en la universidad pertenecía a un grupo de feministas extremistas que acepta- 
ban las opiniones de Cicely Hamilton ${ }^{16}$ y que despreciaban la vida familiar; pero aquí en el lado oeste [de la ciudad] me doy cuenta que mis teorías sobre la familia no coinciden con las situaciones familiares con que me encuentro. Estoy empezando a darme cuenta que, cuando el mundo sea re-hecho, tendrá que tenerse en cuenta algo más que las experiencias de un pequeño cortejo de intelectuales (p. 178).

\section{4. ¿Qué fue la Charity Organization Society (COS)?}

La COS fue una de las respuestas de inspiración cristiana a las condiciones sociales de pobreza en Inglaterra y en Estados Unidos. Fue fundada en 1869 en Londres y en 1877 en Buffalo (Nueva York). Su misión era organizar la caridad privada de tal manera que no denigrara al necesitado, aún más de lo que ya lo estaba, y coordinar los diversos esfuerzos caritativos en un espíritu de colaboración más que de competencia. Partía de la creencia que la limosna pauperizaba a quien la recibía, encerrándole en un círculo vicioso en el que el engañar al que daba la limosna se convertía en un estilo de vida, un estilo de vida desprovisto de dignidad y autoestima. Se creía especialmente peligroso para el pobre su «clientificación» por parte de las numerosas entidades caritativas existentes en los grandes centros urbanos. Esta filosofía moralista, sospechosa del pobre y de la ayuda monetaria, pasa también a Estados Unidos, pero es en este país, sin embargo, donde la COS empieza su andadura hacia una visión científica del problema de la pobreza y hacia la profesionalización de la actividad caritativa. De este giro histórico, Mary Richmond es su pionera y sistematizadora (Woodroofe, 1962).

Richmond es más conocida en la profesión de Trabajo Social por el desarrollo de la metodología profesional con su famoso libro de texto, Social Diagnosis, publicado en 1917. El énfasis de este texto está en el «diagnóstico», en una investigación detallada, "científica»-e intrusiva al extremo-de las familias a las que se iba a ayudar. La idea era ejercer la caridad «científicamente». Una manifiesta contradicción de términos, pero sin duda un reflejo del espíritu científico de la época. Perspicaz como era para tantas cosas, nunca vio una contradicción entre el impulso caritativo que ve radicalmente al otro como a un semejante, como a un hermano, nunca como a un objeto, y el impulso científico que necesariamente objetiviza al individuo y lo rebaja a la categoría de espécimen. Mary Richmond escribió elocuentemente acerca de la relación entre el trabajador social y el cliente $(1899 / 1969 ; 1922)$. Su elocuencia apunta hacia una antropología personalista como la desarrollada por Emmanuel Mounier, Peter Maurin o Dorothy Day ${ }^{17}$, y muy recientemente por Juan Pablo II. Pero Mary Richmond nunca resolvió el dilema entre la amistad y el personalismo que postulaba la relación del profesional con el necesitado por una parte, y la intensa objetivación que proponía su método por la otra (Richmond, 1917).

La COS desapareció totalmente como organización cuando la Gran Depresión de los años 1930 obligó al gobierno federal a tomar cartas en el asunto de la pobreza con la aprobación del Social Security Act en 1935. Se inicia entonces un nuevo capítulo en la historia del bienestar social en el país (Popple y Leighninger, 2002). El triunfo del Estado de bienestar hizo innecesaria la filantropía privada, entendida como Mary Richmond la entendía, pero pervive en la metodología básica del trabajo de casos (recogida de datos/ información; evaluación/diagnóstico), en intervenciones basadas en la evidencia, preferentemente evidencia científica).

\section{Lecciones y conclusiones}

Mary Richmond vivió en una época de utopías sociales. La ciencia y su compañera la técnica parecían dar fundamento racional a los sueños de lograr una sociedad justa, una humanidad selecta, saludable, rica y feliz. Todo parecía investigable, cuantificable, manejable, tratable, controlable y mejorable, y no a largo plazo. El conocimiento estaba ahí, al al-

16 Cicely Hamilton (1872-1952), escritora feminista y sufragista.

17 Emmanuel Mounier (1905-1950) fundador del Movimiento Personalista; Dorothy Day (18971980) fundadora del Catholic Worker Movement; Peter Maurin (1877-1949), co-fundador del Catholic Worker Movement. 
cance, no había más que aplicarlo ya. Pero «el sueño de la razón produce monstruos». Y así sucedió, por ejemplo, con la promulgación de leyes de esterilización forzosa. Honra a Mary Richmond su circunspección respecto a la utopía eugenésica, al liberalismo matrimonial libertario a espaldas del derecho del débil y de los niños, y a la causa feminista a contrapelo de realidades antropológicas. De todas maneras, fue seducida por la posibilidad de una «caridad científica» y, hasta donde he podido averiguar, no vio la imposibilidad de conciliar la amistad humana -por definición gratuita, personalista, sin más expectativas que la misma amistad-con una metodología que necesariamente objetiviza y controla al individuo.

¿Qué podemos aprender hoy? El Trabajo Social como proyecto occidental está hoy mismo embarcado en utopías tan problemáticas como las que enfrentó Mary Richmond en su día. Las promesas científicas en el campo, por ejemplo, de la biología, desde la fertilización in vitro hasta el aborto selectivo, hacen «racionales» políticas sociales que no son más que el ejercicio de poder por quien más puede. Nada nuevo. La falsa contraposición entre los derechos y el bienestar de la mujer y los derechos y el bienestar de su hijo, son otra muestra de una filosofía pública que favorece al más fuerte. Políticas matrimoniales que ignoran la naturaleza de un contrato que implica a otros además de los dos contratantes, son ahora también temas de debate en el Trabajo Social. Pero el Trabajo Social de hoy, absorbido completamente por la cultura donde ejerce su labor, carece de los recursos mínimos para contraponer una visión distinta. Simplemente el trabajador social, en cuanto tecnócrata, se pone al servicio de la sociedad que le paga y hace ni más ni menos que lo que ésta le pide, en detrimento del más débil y necesitado. Quiero acabar con una cita de Lionel Trilling:

\footnotetext{
Una especie de paradoja de nuestra naturaleza nos lleva, una vez que hemos hecho de nuestros semejantes los objetos de nuestro bien-informado interés, a hacerlos objetos de nuestra lástima, y objetos después de nuestra sabiduría, y finalmente de nuestra coerción (citado en Rittlemeyer, 2011, p. 51).
}

\section{Referencias bibliográficas}

Aranguren, José Luis L. (1952/1980). Catolicismo y protestantismo como formas de existencia. Madrid: Alianza.

Daniel, T. M., Bates, J. H. y Downes, K. A. (1994). History of Tuberculosis. En Barry R. Bloom (ed.) Tuberculosis: Pathogenesis, protection and control. Capítulo 2, pp. 13-24. Washington DC: American Society for Microbiology.

Darwin, C. (1959). Evolution and natural selection. Boston: Beacon Press.

Duff, E. (1967). Social Gospel. En New Catholic Encyclopedia (vol. XIII). Nueva York: McGraw-Hill Book Company.

Holt, M. F. (2002). The Know Nothing Party. Abraham Lincoln Historical Digitization Project.Recuperado de: http://dig.lib.niu.edu/message/ps-knownothing.html. Tomado de la WEB el 16 de mayo 2011.

Leon, S. M. (2005). Preaching Eugenics: Religious Leaders and the American Eugenics Movement.Church history. Recuperado de: http://findarticles.com/p/articles/mi_hb050/ is_4_74ai_n29233702/

Library.thinkquest, recuperado de http://library.thinkquest.org/20619/Irish.html .

MacIntyre, A. C. (1984). After virtue: A study in moral theory. Notre Dame, Ind.: University of Notre Dame Press.

MacIntyre, A. C. (1988). Whose justice? Which rationality? Notre Dame, Ind.: University of Notre Dame Press.

MacIntyre, A. C. (1990). Three rival versions of moral enquiry :encyclopaedia, genealogy, and tradition : being Gifford lectures delivered in the University of Edinburgh in 1988. Notre Dame, Ind.: University of Notre Dame Press.

Popple, P. R. y Leighninger, L. (2002). Social work, social welfare, and American society (5 edition). Boston: Allyn and Bacon. 
Rosen, C. (2004). Preaching eugenics: Religious leaders and the American Eugenics Movement. Nueva York: Oxford University Press.

Richmond, M. E. (1899/1969). Friendly visiting among the poor: A handbook for charity workers. Montclair, New Jersey: Patterson Smith.

Richmond, M. E. (1917/1965). Social diagnosis. Nueva York: The Free Press.

Richmond, M. E. (1922). What is social casework? Nueva York: Russell Sage Foundation.

Richmond, M. E. (1930). The long view. Editado por Joanna C. Colcord. Nueva York: Russell Sage Foundation.

Richmond, M. E. y Hall, F. S. (1925). Child marriages. Nueva York: Russell Sage Foundation.

Richmond, M. E. y Hall, F. S. (1929). Marriage and the State. Nueva York: Russell Sage Foundation.

Sanger, M. (1938). Margaret Sanger: An autobiography. Nueva York: W. W. Norton.

Shultz, S. K. (1999) Foreign Inmigrants in Industrial America. Civil War to the present: American History 102 (Lecture 08). Productor P. Tishler. Recuperado de: http:// us.history.wisc.edu/hist102/lectures/lecture08.html.

Siporin, Max (1968). Mary Richmond, a Founder or Modern Social Work. Essay in Mary E. Richmond. En Friendly visiting among the poor: A handbook for charity workers. Montclair, New Jersey (1969): Patterson Smith. Pp. v-xxix.

Weber, M. (1904-1905/1930/1958). The Protestantethic and the spirit of Capitalism. (Traducción de Talcott Parsons). Nueva York: Scribner.

Weber, M. (2004). Science as a Vocation (1919). En ed. David Owen y Tracy B. Strong. The vocation lectures. Indianapolis: Hackett Pub.

Woodroofe, K. (1962). From charity to social work. Toronto: University of Toronto Press.

Encyclopaedia Britannica (1968). American Civil War. Vol. 1 (730-744)

Rittlemeyer, H. (2011). Top Down. National Review, 63(1), 51-52.

Civil War Home Page. Recuperado de http://www.civil-war.net/pages/1860_census.html 